\title{
CHARACTERIZATION OF ATMOSPHERIC PRESSURE PLASMA TREATED POLYESTER FABRICS
}

\author{
S. Nithya ${ }^{1, *}$ and K. R. Aranganayagam ${ }^{2}$ \\ ${ }^{1}$ Department of Physics, Kumaraguru College of Technology, \\ Coimbatore-641049, TN, India \\ ${ }^{2}$ Department of Chemistry, Kumaraguru College of Technology, \\ Coimbatore-641049, TN, India \\ *E-mail: nithyvj@gmail.com
}

\begin{abstract}
Polyester fabrics are treated in low-temperature plasma. Plasma-treated fabrics displayed a substantial variation in the surface structure. Plasma treated fabrics are grafted by using maleic acid (Mac). X-ray diffraction patterns are used to estimate crystallinity of polyester fabrics. From FTIR studies, it is observed that (-OH) group is induced in case of grafted polyester fabric that enhanced the wettability of the fabric. The enhancement of dye uptake in polyester fabrics was evaluated with the help of the capillary method and this showed an extensive wettability and dyeability. Scanning electron microscopy (SEM) was used to study the morphological characterizations of the treated fibers, which were found to be evident.
\end{abstract}

Keywords: XRD, Plasma, FTIR, wettability, SEM

(C) RASĀYAN. All rights reserved

\section{INTRODUCTION}

Plasma is best known for its aversion to chemical effluents in the industrial processing sector. Plasma treatment is deemed to be an expedient methodology to modify surface properties ${ }^{1}$. This is considered to be a worker-friendly and an environment-friendly method to accomplish surface alteration without altering the bulk properties of various materials ${ }^{2}$. Cold plasma is a partially ionized gas, which is generated in a high voltage electric field at a low pressure. Low pressure allows for relatively long mean free path of accelerated electrons and ions and hence the surface structure of fabrics can be modified ${ }^{3}$. Cold plasma treatments enable the researchers to tailor the surface properties like adhesion, wettability or biocompatibility of numerous polymers by its specific applications ${ }^{4-6}$. The surface changes can be done both physically and chemically in textile fibers with the help of many synchronized processes such as activation, cross-linking, etching and grafting of chemical functional groups, which can be achieved with low-pressure plasma treatments ${ }^{7-10}$. Four major effects such as cleaning effect, generation of free radicals, increased micro roughness and plasma polymerization can be gained with the aid of plasma treatments based on the treatment conditions and the requirements for the processing of the materials. The energetic particles bombard with the polymeric surfaces breaks the covalent bond and leads to the formation of surface radicals on the treated polymer. A number of active chemical functional groups are formed on the surface as a result of the reaction of these surface radicals with that of active species of plasma. These groups react strongly with the hydrogen in water. Thus, this is termed to be the hydrophilic property ${ }^{11}$. The fiber surface-layer is noticed to have the physicochemical properties which would ultimately lead to hydrophilicity or hydrophobia. The high-density textile fabrics made of polyethylene terephthalate (PET) fibers along with its high degree of crystalline nature and its dearth of functional polar groups like $(-\mathrm{COOH})$ and $(-\mathrm{OH})$ on its surface make them not to absorb moisture and it is deemed appropriate to be dyed only at one-atmosphere. The obvious result of these properties is a fiber with poor wettability and that has a low surface free energy. Thus, it is determined that surface modification is a basic requisite in PET fiber fabrics to enhance their hydrophilicity. 


\section{Material and Methods}

\section{EXPERIMENTAL}

Plain weave $100 \%$ polyester fabrics are used in this study. The plasma treatment was carried out with the samples of $500 \mathrm{~mm}$ square dimension. Maleic acid (Mac) (99\%) supplied by Ranbaxy Chemicals, New Delhi is used as a grafting medium. Rectangular polyester fabrics of size $5 \times 5 \mathrm{~cm}$ is inserted into the plasma reactor as shown in Fig-1 and are subjected to air plasma treatment for 5 minutes at a pressure of 0.08 mbar and at an applied potential of $350 \mathrm{~V}$. After plasma treatment polyester fabrics are grafted with Mac.

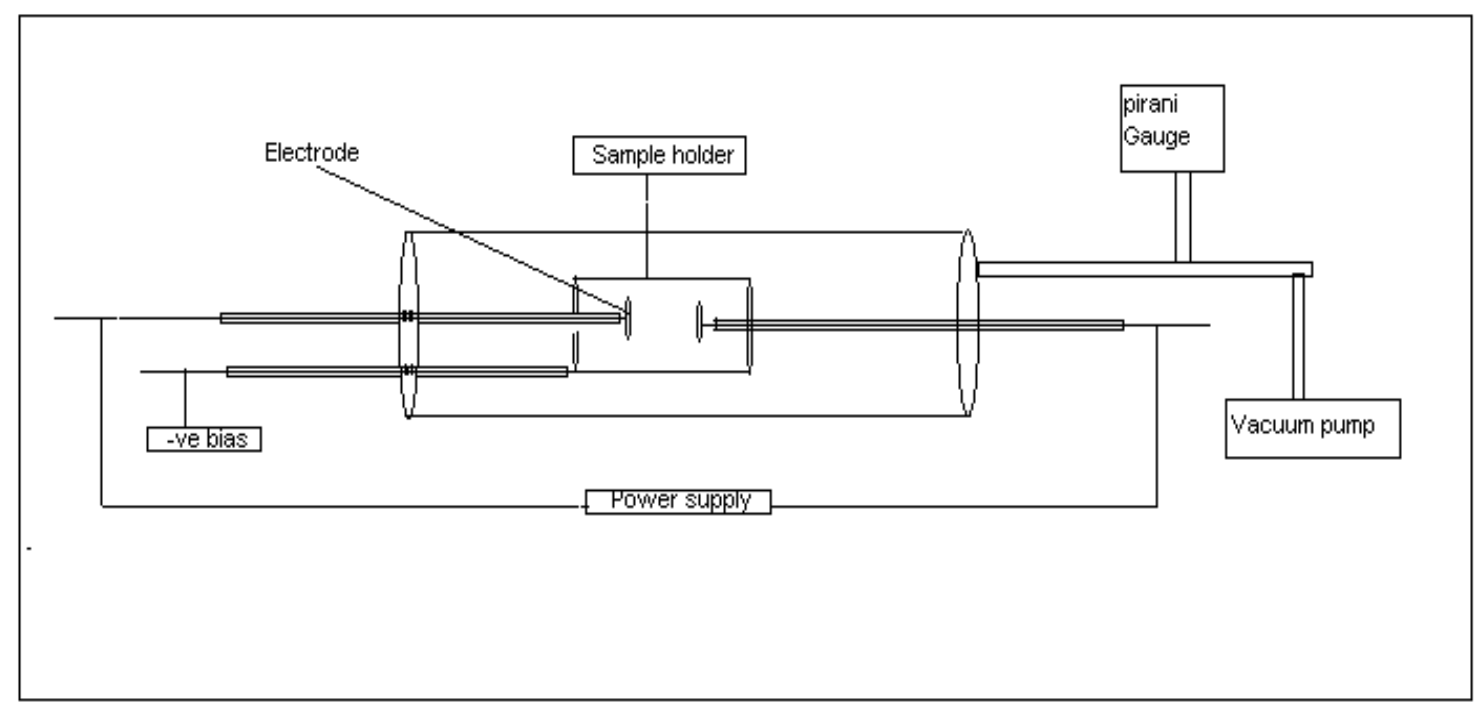

\section{Characterization}

Fig.-1: Schematic view of Plasma Chamber

Samples are analyzed by a Bruker AXS $\mathrm{D}_{8}$ automated X-ray diffractometer, scanned at a rate of $0.3 \mathrm{sec}$ with $\mathrm{Cuk}_{\alpha}$ radiation and are analyzed in the range of $20^{\circ}-30^{\circ}$. A Fourier transform infrared spectrometer (FTIR-8400s SHIMADZU) and standard settings with a Germanium- coated KBR plate are used in this study to detect any changes in the chemical structure at the fabric surface on untreated and plasma treated polyester samples. The spectra are recorded from 400 to $4000 \mathrm{~cm}^{-1}$ with a $4 \mathrm{~cm}^{-1}$ resolution. The morphology of modified polyester fiber is observed on (JEOL JSM-T 330A) scanning electron microscope. The wettability of the polyester fabrics is determined after the plasma treatment using the Capillary rise method.

\section{X-Ray Diffraction}

\section{RESULTS AND DISCUSSION}

For the estimation of polymer crystallinity, crystalline size and its orientation, X-ray diffraction patterns are used. XRD analyses were carried out for both the treated and the non-treated samples which conveyed the result of a minimum decrease in the amount of intensity in the treated fabrics. XRD pattern for untreated and treated polyester fabrics are shown in Fig.-2. The percentage of crystallinity is not decreased noticeably as shown in Table-1, which reveals that the strength of the treated is not reduced compared with untreated fabric.

Table-1: XRD data for polyester samples

\begin{tabular}{c|c|c|c|c|c}
\hline Sample & Condition & $2 \theta$ degree & $\mathrm{d}(\AA)$ & $\mathrm{D}(\AA)$ & FWHM \\
\hline \multirow{3}{*}{ Polyester } & Untreated & 44.215 & 2.0467 & 39.127 & 0.229 \\
\cline { 2 - 6 } & Treated & 14.45 & 6.1247 & 29.992 & 0.279 \\
\hline
\end{tabular}




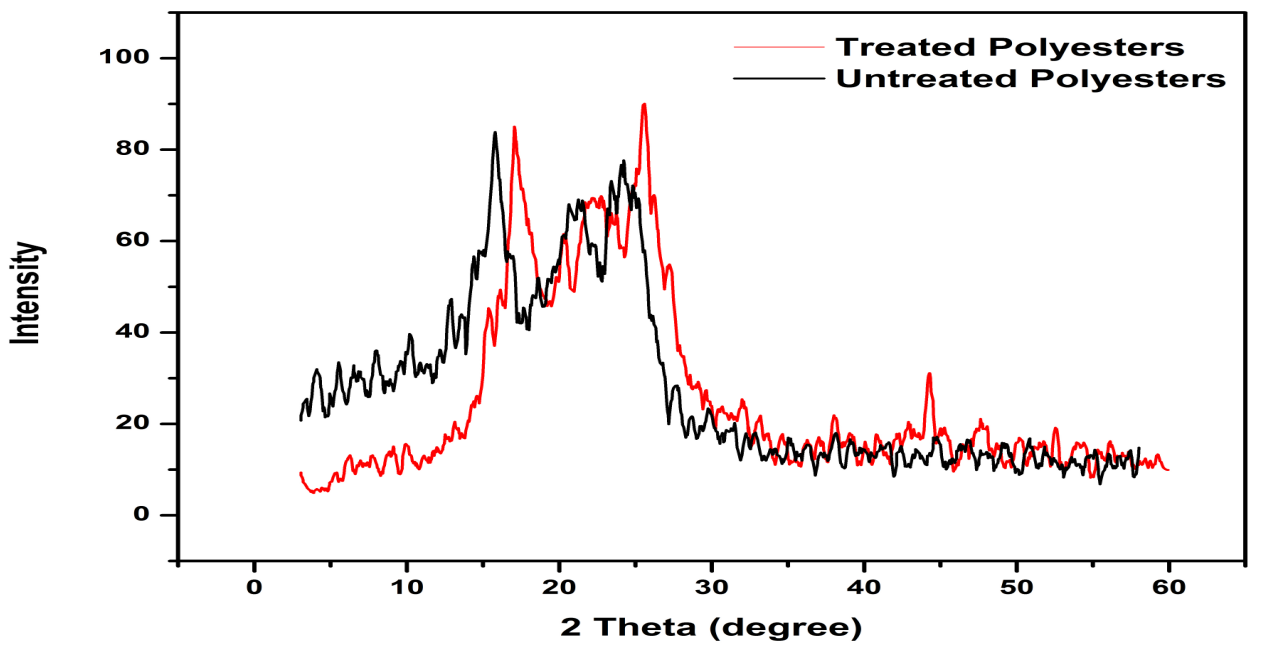

Fig.-2: XRD pattern of untreated and treated Polyester fabric

\section{FTIR spectra}

Small changes in the surface crystallinity due to plasma treatment are investigated by Fourier Transform Infrared spectrophotometer (FTIR). Infrared analysis (Fig.-3a, Fig.-3b and Fig.-3c) reveals that grafted polyester fabrics have a substantial influence on the surface morphology of fabric. In grafted polyester fabric increase in a peak at $3000 \mathrm{~cm}^{-1}$ attributes to asymmetric $\mathrm{O}-\mathrm{H}$ bonding. Presence of polar groups such as $(-\mathrm{OH})$ will enhance wettability and it effectively improves the subsequent dyeing and printing processes.

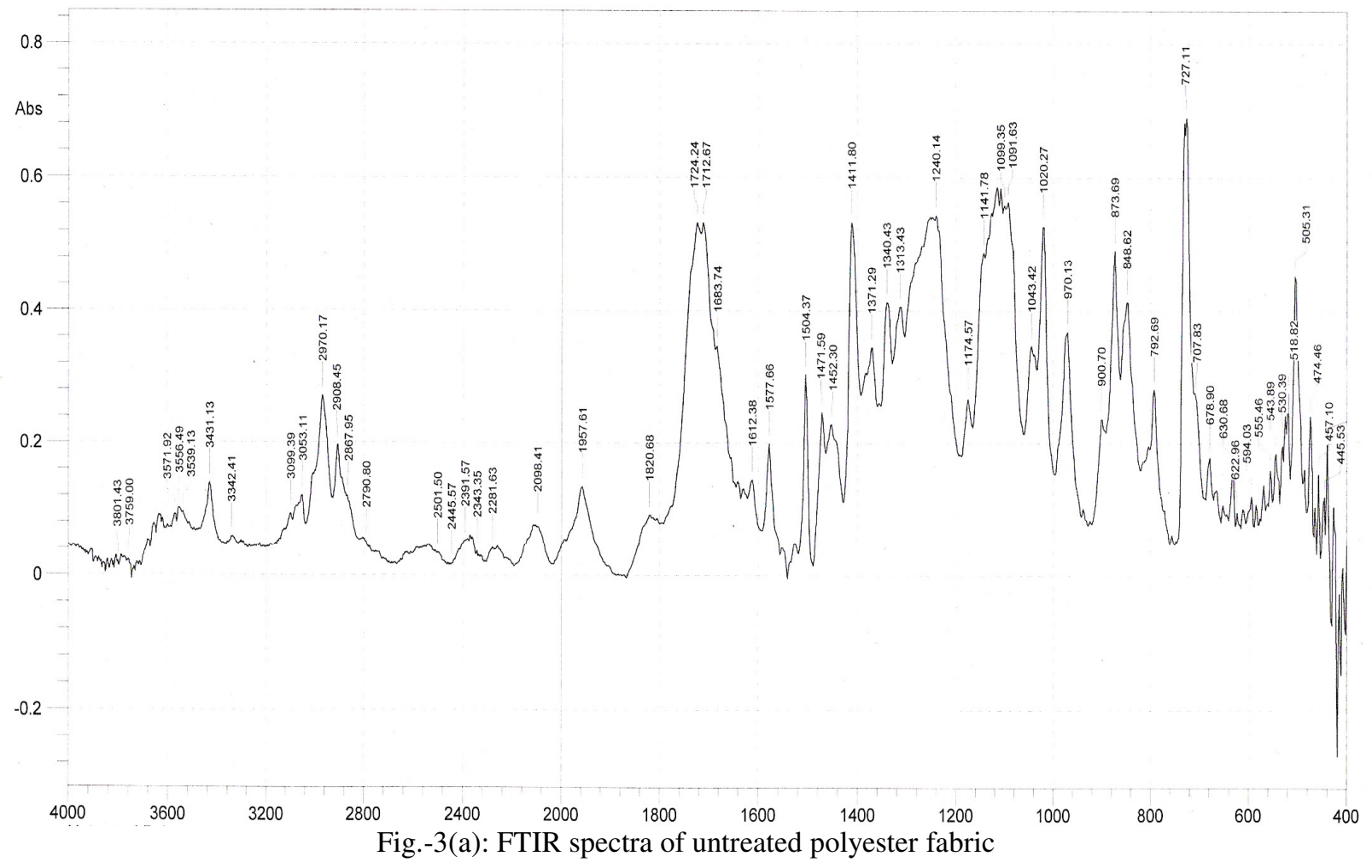




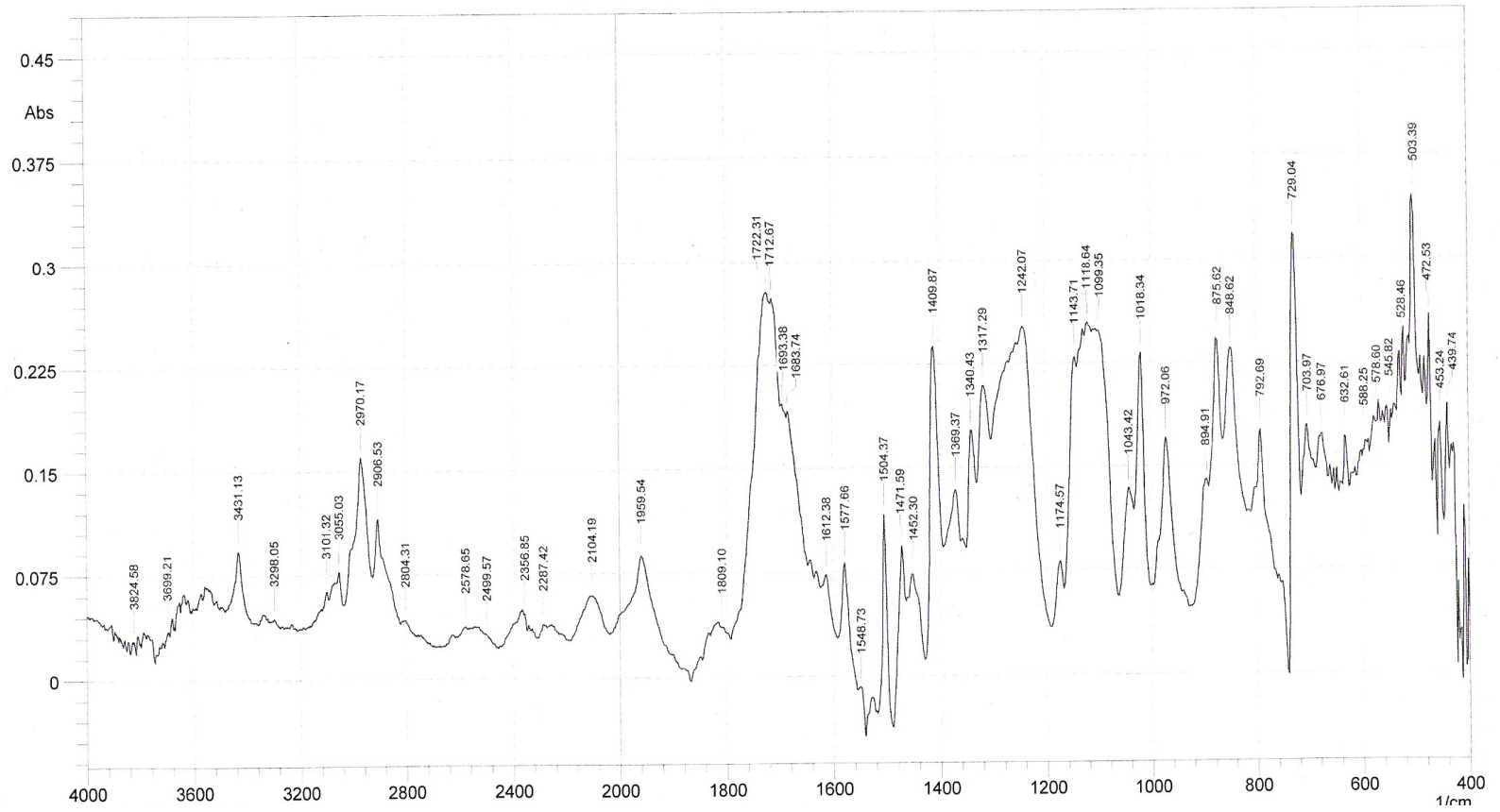

Fig.-3(b): FTIR spectra of plasma treated polyester fabric

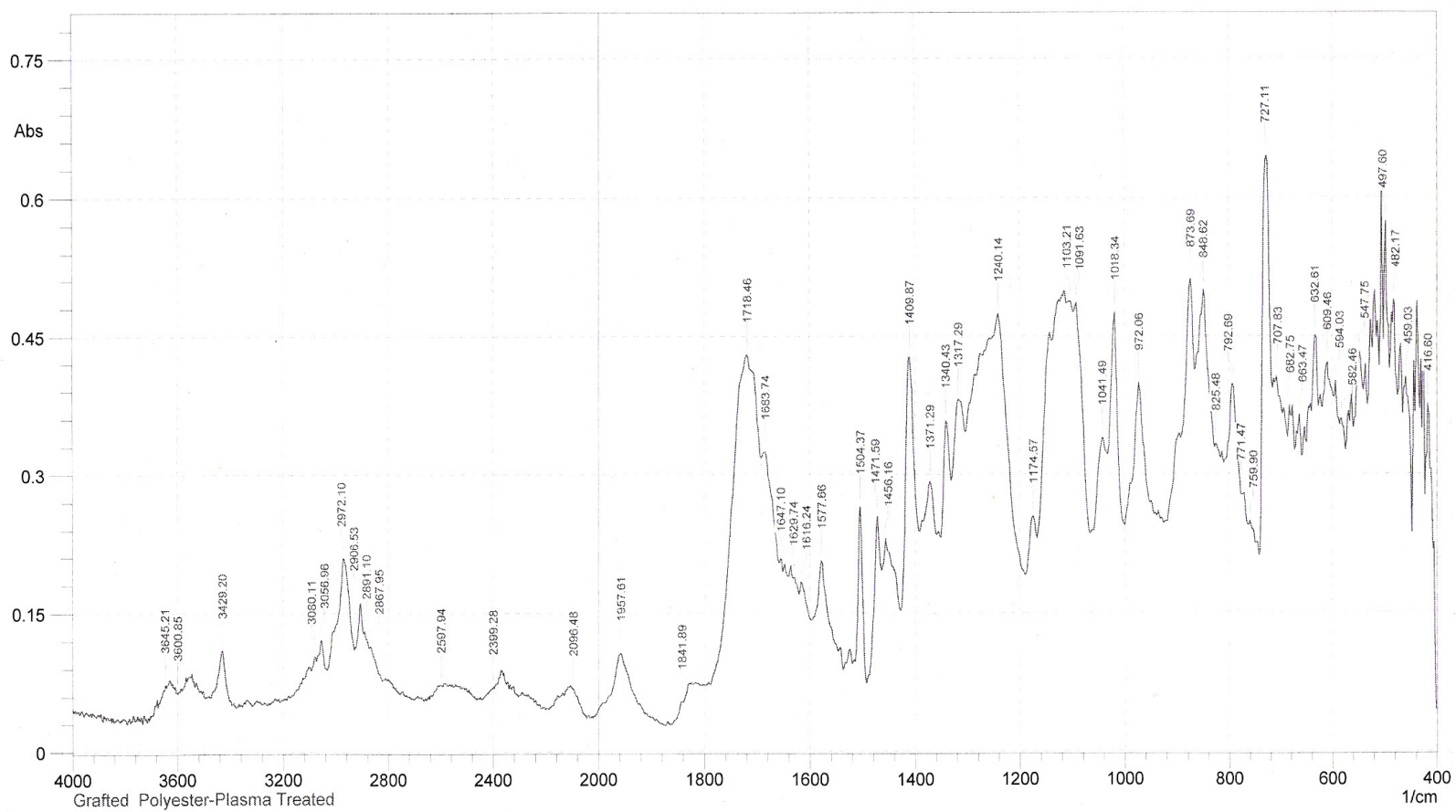

Wettability Measurements

Fig.-3(c): FTIR spectra of grafted polyester fabric

The plasma discharge is an extensively used phenomenon to enhance the hydrophilicity and/or wettability of a number of textile materials ${ }^{12,13}$. The polyester samples are subjected to wettability test, the capillary rise method, soon after the plasma treatment. A vertical fabric strip with its lower end dipped in a dye solution in a small beaker is the simple wettability test. This process initiated a spontaneous wicking as a result of the capillary forces and the readings of absorption height were taken consequently. 
The treatment exposure time was varied in the range of 2 to 10 minutes in the present study. The gas pressure was maintained at 0.08 m.bar, and the discharge voltage was maintained at $350 \mathrm{~V}$ for all the measurements. Dye uptake data of plasma treated polyester fabrics versus treatment time for the given experimental conditions is shown in Fig.-4. From the graphs, it is observed that increase in treatment time improves the dye uptake of plasma treated and grafted polyester fabrics.

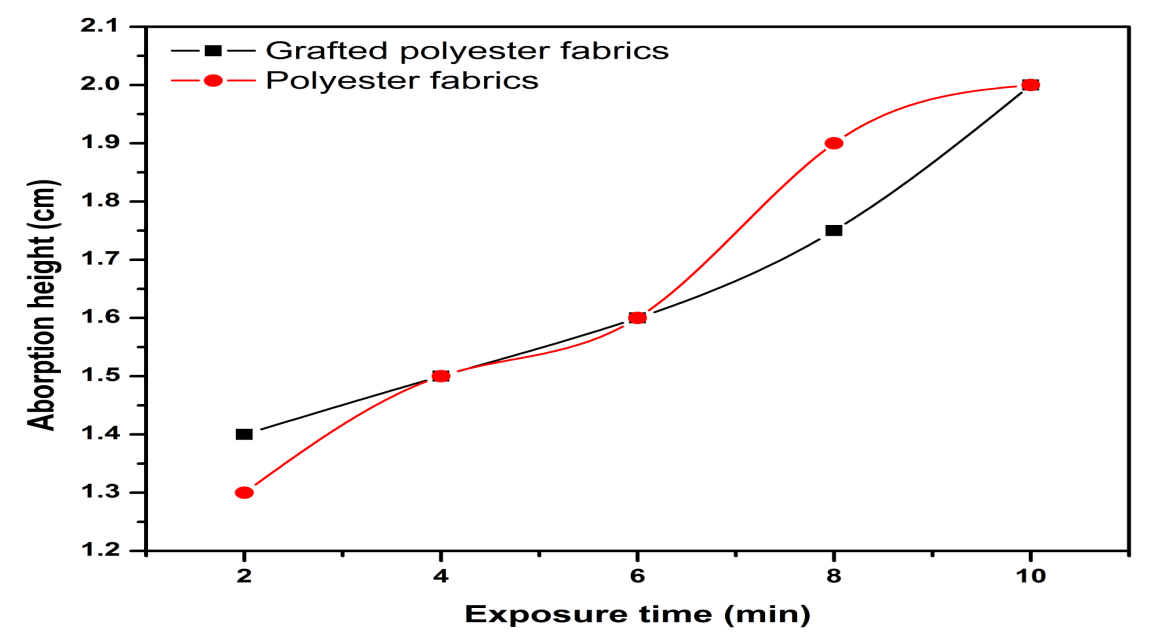

\section{SEM Analysis}

Fig.-4: Effect of treatment time on wettability

Fig.-5 shows the longitudinal SEM micrographs of untreated, treated and grafted polyester fibers. As seen here, surface morphology significantly changes after plasma treatment due to deposition of a thick film on the surface of the fabric fibers. Scanning electron microscopy (SEM) discloses that the etching effects are minimum in the fabric and also an important feature to maintain the softness in the textile.
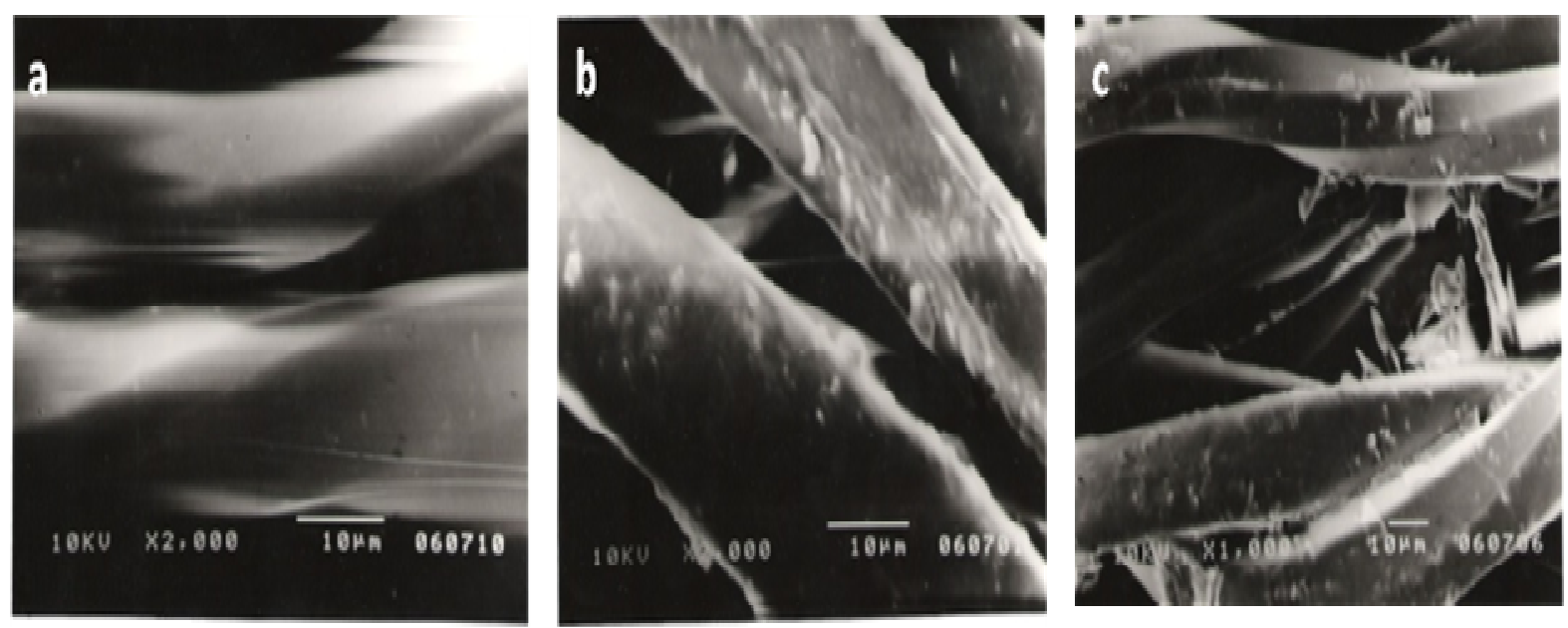

Fig.-5: SEM image - (a) Untreated Polyester fabric, (b) Treated Polyester fabric, (c) Grafted polyester fabric

\section{CONCLUSION}

Surface modifications of polyester fabrics by atmospheric plasma are investigated. It is evidently observed from the XRD results, that there is a decrease in the percentage of crystallinity on the surface of plasma treated polyester fabrics. The plasma treatment was found to be adequate to enhance the wettability of the polyester fabrics. The FTIR studies state that the hydroxyl group that is encouraged in the category of grafted polyester fabric has given improvement and enrichment in the wettability of the 
fabric. The SEM results evidently show that the surface of the plasma treated polyester fiber has the deposition of a thick film.

\section{REFERENCES}

1. Dattatray S. Wavhal and Ellen R. Fisher, Langmuir, 19(1), 79 (2003), DOI: 10.1021/la020653o

2. Y. Seki, M. Sarikanat, K. Sever, S. Erden, H. A. Gulec, Fibers and Polymers,11(8), 1159 (2010), DOI: $10.1007 / \mathrm{s} 12221-010-1159-5$

3. Carrie Cornelius, Marian McCord, Mohamed Bourham, Peter Hauser, Cellulose, 25,869 (2018), DOI:10.1007/s10570-017-1586-1

4. Elena Selli, Giovanni Mazzone, Cesare Oliva, Federica Martini, Claudia Riccardi, Ruggero Barni, Bruno Marcandallic and Maria Rosaria Massafrac, J. Mater. Chem., 11, 1985 (2001), DOI: 10.1039/B101360M.

5. R. Molina, J.P. Espinos, F. Yubero, P. Erra, A.R. Gonzalez-Elipe, Applied Surface Science, 252, 1417 (2005), DOI: 10.1016/j.apsusc.2005.02.147

6. A. Raffaele-Addamo, C. Riccardi, E. Selli, R. Barni, M. Piselli, G. Poletti, F. Orsini,B. Marcandalli, M.R. Massafra, L. Meda, Surface and Coatings Technology,174-175, 886 (2003), DOI: 10.1016/S0257-8972(03)00364- 5

7. G. Poletti, F. Orsini, A. Raffaele-Addamo, C. Riccardi, E. Selli, Applied Surface Science,219, 311 (2003), DOI:10.1016/S0169-4332(03)00703-7

8. Poletti, F. Orsini, C. Riccardi, A. Raffaele-Addamo, R. Barni, Surf. Interface Anal., 35, 410 (2003), DOI: $10.1002 /$ sia. 1543

9. A. Demir, Y. Seki, E. Bozaci, M. Sarikanat, S. Erden, K. Sever, E. Ozdogan, J. Appl. Polym. Sci., 121, 634 (2011), DOI: 10.1002/app.33220

10. C. S. Ren, D. Z. Wang, Y. N. Wang, J. Mater. Process. Technol., 206, 216 (2008), DOI:10.1016/j.jmatprotec.2007.12.012

11. N. Inagaki, Plasma Surface Modification and Plasma Polymerization, Technomic, Lancaster, Pa., 1995.

12. H. K. Yasuda, Plasma Polymerisation and Plasma Treatment of Polymers, Wiley, New York, 1987.

13. A. Grill, Cold Plasma in Material Fabrications, The Institute of Electrical and Electronics Engineers, New York (1993).

[RJC-2092/22018] 